\title{
LXXXVI. On indigogene
}

\section{J. Murray Esq.}

To cite this article: J. Murray Esq. (1816) LXXXVI. On indigogene, Philosophical Magazine Series 1, 47:218, 415-416, DOI: 10.1080/14786441608628497

To link to this article: http://dx.doi.org/10.1080/14786441608628497

$$
\text { 曲 Published online: } 27 \text { Jul } 2009 .
$$

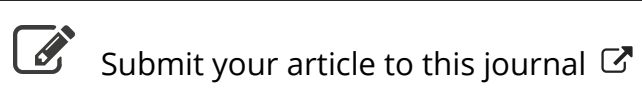

\footnotetext{
Џ Article views: 2
}

Q View related articles $\asymp$ 
apartment and the currents of cold air from the chimney acting on the surface of the body, and in the cases of rheumatism, more particularly, defeating the object for which the warm-bath was prescribed.

When walking over the building, we had an opportunity of examining a model of a chemical apparatus for producing chatybeate u ater, by Galvanic action; but as we were informed, consideralle improvements were making on the larger apparatus, we will take an early opportunity of laying a description of it before our readers.

The last and not the least improvement in this establishment is the very moderate sum which is intended to be charged for each bath. Those who have been accustomed to frequent Brighton for cheapness, will now here be agreeably surprised at finding infinitely superior accommodation for the same money.

\section{On Indigogene. By J. Murrax, Esq.}

\section{To Mr. Tilloch.}

$S_{1 R,-}-I_{\text {BEG to submit some remarks on the substance called }}$ by Brugnatelli indigogene.

It is obtained from indige, a substance one of the products of the Indigofera and Isatis, and the varied species of which are matives of the East Indies, Cape of Good Hope, and New Holland. The extract from the letter of M. Van Mons of Brussels, in the Philosophical Magazine, first called my attention towards this curious body.

If indigo in the form of powder be projected on a red hot iron, a vapour of a blueish colour arises, and a red shade passes over the surface of the iron. This vapour exhales a peculiar odour smewhat resembling burnt malt; and when condensed, the indigogene is evolved under the form of fine ncedlelike crystals of a copper colour and lustre: viewed through a lens, sometimes arborescent groups appear. The mode which I adopt for procuring the indigogene is as follows:

A small glass capsule (a watch glass will suit) containing the powdared indigo is set in one of the sliding rings of the stand usuainy accompanying an Argand's lamp. A flat piece of glass is placed on the capsuie, and it is then submitted to the action of heat. Water is first given off, then succeeds a reddish vapour, which attaches to the flat piece of glass (from which it is difficultly removed by spirits of turpentine); and ultimately, after the heat has been cousiderably increased, the substance in question 
is seen to pervade the surface of the indigo (which becomes a crust). It may be detached by means of a delicate spatula. The odour at first is unpleasant, but it becomes more mild and somewhat like that of sweet wort; or it may be obtained by heating indigo on a metallic plate. I have seen similar crystals on the sides of the indigo vat, from whence it seemed to have stiblimed.

I find that indigogrene is readily soluble in sulphuric acid and also in nitric acid, communicating to each a green colour. It is not soluble in muriatic acid, nor in a solution of boiling caustic potassa, nor in ammonia.

It is soluble in olive oil, even when cold, and in naphtha and cajeput oil with the assistance of heat. Ammonia added to the solution in oil of olives does not materially evolve the substance, but from naphtha and cajeput oil it is disengaged unaltered.

Indigogene is solnble in hot alcohol and sulphuric ether. It is instantly dissolved by an alcoholic solution of camphor being increased by heat, but is not so soluble in soap dissolved by spirit, communicating to these a blue tinge.

Indigogene when projected on melted nitrate of potassa detonates, and slightly explodes when mixed with oxymuriate putassa on the contact of sulphuric acid.

Indigogene does not combine with mercury by simple triture, but forms an amalgam aided by heat. Before the blowpipe when in a platina spoon it scintillates and inflames, a violet vapour evolves, and a blue shade crowns the surface of platina.By percussion with oxymuriate potassa it fulminates with flame. 'The effects of various reagents may form the subject of a future paper.

Liverpool, June 8, 1816.

$$
\text { I am, Src. }
$$

J. MURray.

LXXXVII. On the State of the Manufacture of Sugar in France. By M. le Comle Chaptal.

[Concluded from p. 339.]

The boiler into which the clearcd juice falls should be about eight feet long, five and a half wide, and twenty-two inches deep. As soon as the bottom of this boiler is covered with the liquid, the fire is lighted, and the heat raised to ebullition as quick as possible. The instant the liquor begins to boil, sulphuric acid, diluted with twenty parts of water, is poured into it, in the proportion of a tenth part of the lime employed; the whole must 